\title{
Interactions between hormonal contraception and single or intermittently dosed rifampicin: a pharmacokinetic modelling and simulation study
}

Jeremy Hill ${ }^{1}$, Kendra Radtke ${ }^{2}$, Anne Schoenmakers ${ }^{3}$, Christiaan Mulder ${ }^{1}$, Emmy van der Grinten $^{1}$, Floor Overbeek ${ }^{3}$, Nicole Salazar-Austin ${ }^{4}$, Wilcare de Medeiros Cordeiro

Nascimento ${ }^{5}$, Wim van Brakel $^{3}$, and Ethel Weld ${ }^{4}$

${ }^{1} \mathrm{KNCV}$ Tuberculosis Foundation

${ }^{2}$ University of California San Francisco

${ }^{3} \mathrm{NLR}$

${ }^{4}$ Johns Hopkins University School of Medicine

${ }^{5}$ Erasmus University Rotterdam

January 21, 2022

\begin{abstract}
Aim Scale up of rifampicin-based prevention regimens is an essential part of the global leprosy strategy. Daily rifampicin may reduce the effectiveness of the oral contraceptive pill (OCP), but little is known about rifampicin's effects at the less frequent dosing intervals used for leprosy prophylaxis. Since many women of reproductive age who are eligible for rifampicin-based regimens rely on OCP for family planning, additional information characterising the interaction would enhance scalability and acceptability of leprosy prophylaxis. Methods We used a semi-mechanistic pharmacokinetic model to predict the expected induction effect of rifampicin on OCP oral clearance (CL/F) when used for leprosy prophylaxis. Rifampicin dosing schedules were selected based on WHO-recommended and investigational leprosy prophylaxis regimens. Uncertainty in the model was explored using a scenario analysis. Results Hormonal contraceptive CL/F with rifampicin given as a single $600 \mathrm{mg}$ dose, a single $1200 \mathrm{mg}$ dose, or as $600 \mathrm{mg}$ once every four weeks was predicted to increase by a maximum of $12 \%, 14 \%$ and $14 \%$, respectively, and return to baseline before the next dose. Hormonal contraceptive CL/F was predicted to increase by $>20 \%$ with once-weekly and once-daily dosing of $600 \mathrm{mg}$ rifampicin. Using a threshold of $20 \%$, rifampicin used for leprosy prophylaxis does not have a clinically relevant interaction with OCP. Conclusion These modelling study findings suggest that women using OCP can expect efficacy to be maintained with coadministration of rifampicin-based leprosy prophylaxis and should provide reassurance to stakeholders that leprosy prophylaxis need not be accompanied by any additional specific recommendation about use of OCP.
\end{abstract}

\section{Hosted file}

Article_Rifampicin_OC 220112 uploaded.docx available at https://authorea.com/users/ 456503/articles/553518-interactions-between-hormonal-contraception-and-single-orintermittently-dosed-rifampicin-a-pharmacokinetic-modelling-and-simulation-study 

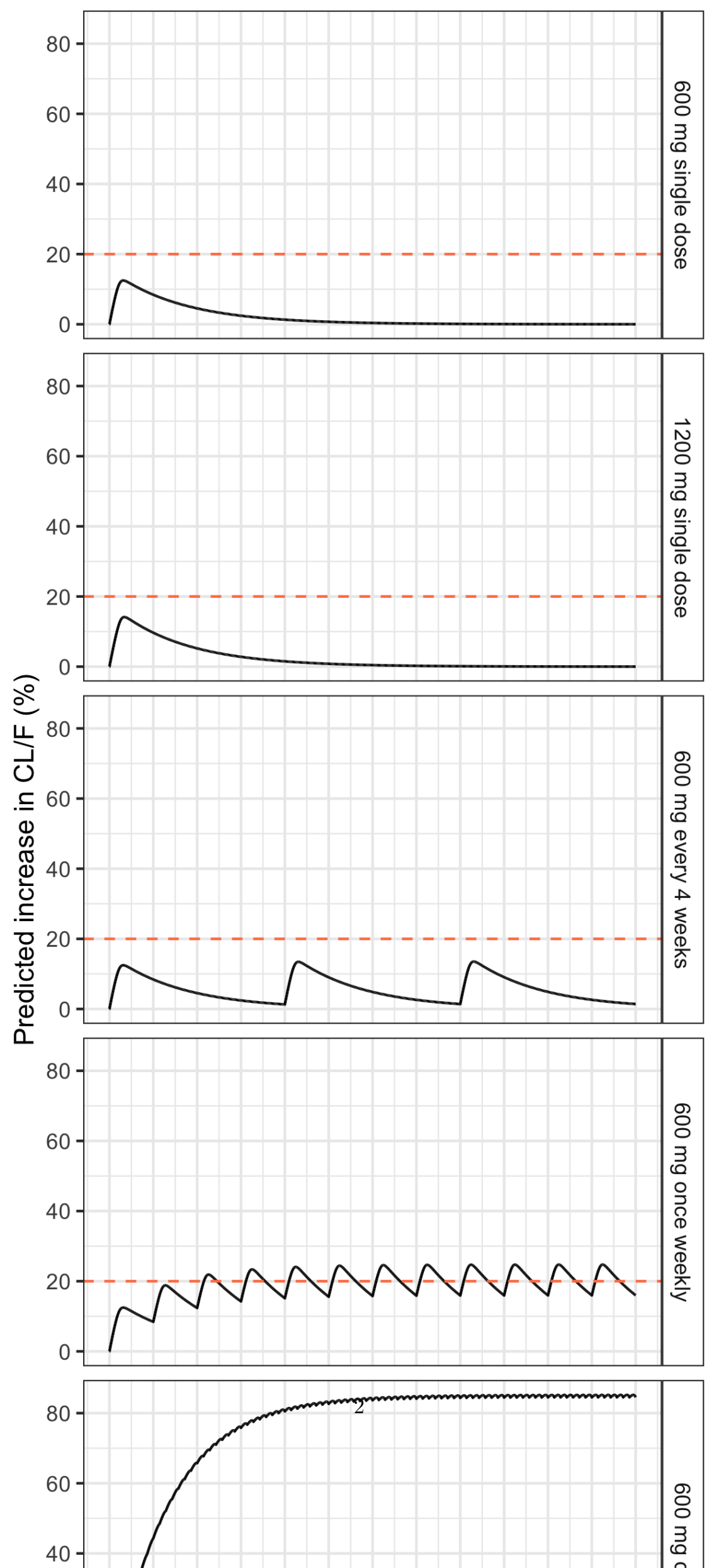
Rifampicin 600 mg every 4 weeks for 1 year

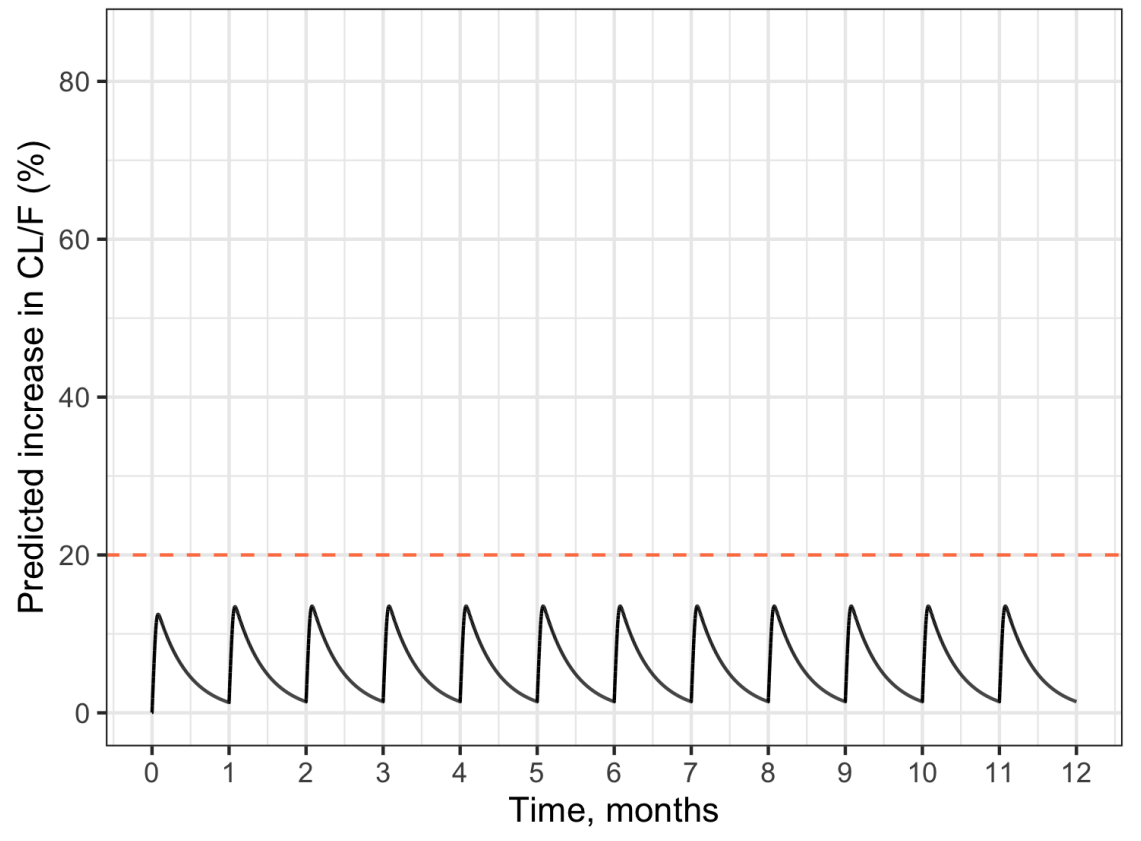

